\title{
TAKEOVERS AND COOPERATIVES:* Governance and Stability in Non-corporate Firms
}

\author{
David Kelsey \\ Department of Economics \\ Frank Milne \\ University of Exeter, England \\ Department of Economics \\ Queens University, Canada.
}

11th January 2010

\begin{abstract}
If consumers wholly or partially control a firm with market power they will charge less than the profit maximizing price. Starting at the usual monopoly price, a small price reduction will have a second order effect on profits but a first order effect on consumer surplus. Despite this desirable static result, it has been argued that cooperatives are vulnerable to take-over by outsiders who will run them as for-profit businesses. This paper studies takeovers of cooperatives. We argue that there will not be excessive takeovers of cooperatives due to the Grossman-Hart problem of free riding during takeovers.
\end{abstract}

Address for Correspondence David Kelsey, Department of Economics, University of Exeter, Rennes Drive, Exeter, Devon, EX4 4PU, ENGLAND.

Keywords, corporate governance, cooperative, take-over, free-rider, externality.

JEL Classification: D70, L20.

\footnotetext{
${ }^{*}$ Research in part supported by ESRC grant RES-000-22-0650. We would like to thank the referees and editor of this journal for their helpful comments.
} 


\section{INTRODUCTION}

\subsection{Background}

In many cases production is not organized in conventional for-profit joint stock companies. The alternatives include worker and consumer cooperatives, partnerships, not for profit firms and even joint stock companies where the shares are owned by trading partners. Moreover smaller limited companies often deviate from the textbook model of profit maximization. These differences between types of organization do not appear random (for instance driven by political tastes) but instead are systematically related to the type of industry in which firms operate. Moreover these organizations seem relatively stable and persist over long periods of time.

Cooperatives have been shown to have desirable static properties, since they can often reduce market distortions such as those due to monopoly or externalities, see for instance, Hart and Moore (1996), Roemer (1993) or Renstrom and Yalcin (2003). However it is often argued that cooperatives have unsatisfactory dynamic performance since they do not have the correct incentives for investment and are vulnerable to takeover by an outsider who aims to convert them into profit maximizing firms, see Farrell (1985). The present paper takes up the second issue and argues that cooperatives may be less vulnerable to the threat of take-over than previously believed.

Hansmann (1996) cites a number of examples where firms are owned by those who trade with them either on input or output markets. He argues that, in many cases, this is to counter monopoly or monopsony power. This practice is very common among firms, which supply inputs to or buy produce from farms. Refsell (1914) explains in detail how cooperative grain elevators came to dominate the mid-west. Their share of the industry expanded rapidly at the expense of for-profit rivals during the period 
1903-1913. It is clear from his account that the main reason for this was a response to monopoly pricing by for-profit grain elevators. In relatively remote rural areas, it is easier to establish a local monopoly. This is not an isolated example. Cooperatives supply inputs to farms and purchase their produce in many countries. Some of them have forward integrated into processing distribution and marketing and as a result have become quite large organizations. A number of well-known brand names have been developed by farmers' cooperatives such as Welchs, Sun-Maid and Sun Kist. ${ }^{1}$

The reason that such organizations come into existence and thrive is that in relatively remote rural areas competition is not possible due to the small scale of the market. If these businesses were organized on a for-profit basis they would have monopoly power. Farm cooperatives (at least partially) internalize the distortion and thus bring about an improvement in allocative efficiency. For similar reasons many professional services, such as lawyers and accountants, are provided by partnerships. A possible explanation is that the firm is a monopoly supplier of inputs such as client lists, which these people need to work. Partnerships reduce the distortion in prices. Viewed this way a legal partnership has some features in common with an agricultural cooperative.

\subsection{Monopoly Power and Cooperatives}

This paper is related to the general equilibrium literature on imperfect competition, see for instance Gabszewicz and Vial (1972). In general equilibrium with imperfect competition the Fisher Separation Theorem breaks down. Shareholders will typically not wish the firm to maximize profits. ${ }^{2}$ This is because with imperfect competition the firm's decisions will, in general, affect prices throughout the economy. Shareholders

\footnotetext{
${ }^{1}$ For further details see Hansmann (1996) Ch. 7.

${ }^{2}$ See especially Gabszewicz and Vial (1972) p395.
} 
will be affected by the firm's decisions both because their incomes depend on profits and because the firm can directly affect the prices they face. In general the second effect is non zero hence they will not wish to maximize profit but also take account of the firm's impact on prices. In such circumstances a profit maximizing firm may yield lower utility to shareholder/consumers than another form of organization.

These arguments show that consumer ownership of monopolies may be beneficial, see, Demichelis and Ritzberger (2006), Farrell (1985) and Kelsey and Milne (2008). In circumstances where competition is not possible, monopoly distortions are reduced without government intervention. Consider a firm that is the sole producer of a particular good. Suppose that consumers have a substantial influence over its pricing and output decisions. It is in the interest of consumer-shareholders to set the price below the monopoly level, since a small price reduction will result in a second order loss of profits but a first order gain in their consumer surplus. If a firm faces input markets which are imperfectly competitive, then a similar argument establishes it may be desirable to give input suppliers influence in decisions.

A number of different legal arrangements may serve to give consumers and/or suppliers influence in decision-making. If the input concerned is a form of labour, the firm could be a worker cooperative or a partnership. Professional partnerships serve to supply only those kinds of labour for which there is a market distortion, while other kinds of labour can be hired on a standard wage contract. Consumer cooperatives would serve to control monopoly power in output markets. Alternatively the interested parties could hold blocks of shares in a limited liability company. ${ }^{3}$

\footnotetext{
${ }^{3}$ The latter possibility is discussed in more detail in section 3.3.
} 


\subsection{Stability of Cooperatives}

Despite the desirable static properties of consumer ownership it has been argued that such a firm will not be stable in the long-run. For instance, Farrell (1985) argues that consumer-controlled monopolies may be vulnerable to takeover. ${ }^{4}$ To understand his argument, consider a consumer-owned monopoly, which is selling below the profitmaximising price. Farrell argues that a raider (who is not a consumer) could buy up shares at the current value and then make a profit by increasing the product price, thereby increasing the value of his/her shares. This will reduce the utility of a majority of the members of the cooperative. Although they sell their shares at a premium, the subsequent price rise will reduce their consumer surplus. It is possible that a member who only makes small purchases of the firm's output will gain. However total surplus is reduced since, aggregated over all ex-ante members of the cooperative, the losses out-weight the gains. There is, in addition, a redistribution of wealth from the members of the cooperative to the raider. Thus there is a strong presumption that social welfare is reduced.

The members of the cooperative will typically be worse off if the takeover succeeds, however Farrell argues that they will accept the raider's offer because the output price is a public good for shareholders. As usual, free-rider problems imply that they will not internalize the benefits to others of a low price and hence will accept the offer.

Corneo (1997) argues that the because of the vulnerability of cooperatives to takeover, a publicly owned firm might be superior. In his model there is a publicly owned firm with increasing returns to scale. Corneo assumes that prices are determined by the median voter. This could be the result ether of direct or indirect democracy. In this context, marginal cost pricing is (first-best) efficient but will result

\footnotetext{
${ }^{4}$ See also Dow and Skillman (2007).
} 
in losses, which need to be financed through general taxation. For similar reasons to that already discussed in the context of cooperatives, the median voter rule will result in a price below the profit maximizing monopoly level. However majority voting will only result in marginal cost pricing if the mean and median voter have the same preferences. Our result says that if the median voter gets less benefit from the cooperative than the mean voter it is profitable for the raider to buy up the shares of the $50 \%$ of the members who get least benefit from the cooperative and convert it into a profit maximizing firm. For a public firm takeovers are not possible. However the protection afforded by public ownership is not absolute since there is always the possibility of privatization. If the median taxpayer received less benefit from public ownership than the mean taxpayer then there may be political pressure to privatize the firm. ${ }^{5}$ In other words these arguments suggest that privatization is more likely for publicly owned firms which tend to benefit better off tax-payers.

Although Farrell's argument that cooperatives are vulnerable to takeover is logically correct, it does not appear to be supported by the evidence. Cooperatives, partnerships and similar organizations have dominated many lines of business over long periods of time. Thus it does not always seem to be the case that cooperatives are unstable. Nor is it necessarily true that for-profit firms tend to take over an industry. As noted above, in the twentieth century cooperatives took over much of the trade with farms in rural areas in the USA and a number of other countries.

There have been some instances where cooperatives have been restructured as for profit businesses. However often these appear to be driven by changes in regulation and/or tax law, not any intrinsic instability of cooperatives. For instance, in the recent past in the UK and Australia, building societies (mutual banks) have been

\footnotetext{
${ }^{5}$ Corneo (1997) assumes preferences are quasi linear, which implies rich individuals have the same demand as the less well-off. This comment applies to a possible extension of his model where this assumption is relaxed.
} 
replaced by for-profit banks. This change occurred because the building societies lost a long standing tax advantage. Overall we believe that these industry structures do not appear to be as unstable as Farrell's argument suggests.

Hansmann (1996) shows that mutual banks and insurance companies gained business at the expense of for profit rivals in the nineteenth century. He argues that this was because they had superior monitoring abilities, which enabled them to control moral hazard. In particular the nature of the deposit contract meant that for-profit banks have an incentive to make excessively risky investments. If successful, the bank owners take all the gains, while depositors bear the bulk of the losses if the investments fail. In a mutual bank, which could be a trust or a cooperative of depositors, there is no residual claimant. Thus the potential gains from risk-taking are reduced. Mutual banks also had superior abilities to control moral hazard by borrowers. Throughout the twentieth century increased regulation reduced the scope for moral hazard. In particular widespread deposit insurance gave savers less reason to prefer mutual banks. As result they became less common. ${ }^{6}$

\subsection{Takeovers of Cooperatives}

In the present paper we study takeovers of cooperatives. The model is based on a twostage game between a raider and the members of the cooperative. In the first stage, the raider decides whether to make an offer for the members' shares and how much to bid. Secondly the members simultaneously decide whether or not to accept the offer. We show that raider can only take over the firm if (s)he can increase its value by more than the benefit the median shareholder gets from the cooperative. If the

\footnotetext{
${ }^{6}$ This regulation was partly counter-productive. Mutual savings and loans had a significantly lower default rate during the US savings and loans crisis of the 1980's. Despite this they were charged the same premiums for deposit insurance as for-profit rivals.
} 
median and mean members have the same preferences this implies that takeovers will only occur if they maximize total surplus. Or equivalently takeovers can only cause inefficiency when the preferences of the median and the mean member are different. We also study a sequential model which demonstrates that our results are reasonably robust in the sense that they do not depend crucially on the sequence of moves.

Suppose in the initial situation the cooperative chooses its price to maximize the total surplus of its members. This will involve pricing below the monopoly level. Let $\pi_{o}$ denote the value of the shares in the initial situation. If the firm raised prices to the profit maximizing level, then the value of its shares would increase to $\pi_{1}>\pi_{o}$. Consider the possibility that a raider offers to buy the shares at price $q$, per share, and increase the value by reorganising the former cooperative as a profit maximizing firm. For the raider to be able to make a profit it is necessary that $\pi_{1}>q>\pi_{o}$.

Farrell (1985) identifies the following problem: if each member of a large cooperative decides individually whether or not to accept the raider's offer, then any given member will prefer a small premium over the current market price and (s)he will see the success or failure of the takeover as independent of his/her own decision, (i.e. an individual does not take into account that his/her decision might be pivotal to turn a failure of the takeover into a success) and might eliminate the total benefit to members of being able to buy the good at a low price.

In the present paper we identify a similar effect which gives an individual member an incentive to reject the offer. Suppose that a given member does not take into account the possibility that his/her decision may affect the success or failure of the takeover. The given member will prefer to reject the offer and wait to get the posttakeover price $\pi_{1}$ rather than accept the offer now and receive $q<\pi_{1}$. In other words the given member does not take into account the possibility that his/her decision 
might be crucial for the success or failure of the takeover. The second effect is similar to the free-riding problem identified by Grossman and Hart (1980).

Organization of the paper The next section contains our main model of takeovers. Section 2.4 discusses some limitations of the model in particular the assumption that information is symmetric. Our conclusions can be found in section 3, which discusses how our analysis may be extended from imperfect competition to other market distortions. The appendix contains the statements and proofs of some technical lemmas used to establish the main results.

\section{TAKEOVERS}

We consider a firm, which is the sole producer of a good or service. Suppose the firm is initially organized as a cooperative, we show that provided the preferences of the members are not too diverse, it is not a profitable strategy to take it over and reorganize it as a profit-maximizing firm.

In addition to cooperatives we wish to study other situations where production is undertaken by organizations which are not conventional for-profit joint stock companies. It is impractical to model all of the possible cases in detail. Instead we have focused on one central case. The key assumptions are that shares can be traded and that once the raider has the support of a majority of shares he can take control. These are chosen because they are, if anything, favourable to the raider. Even in this case, we find that there is no reason to believe that the number of takeovers will be excessive. We shall discuss how our results would change with different assumptions in section 2.4 . 


\subsection{Model}

Consider a cooperative of $M$ individuals or members, $1 \leqslant i \leqslant M$. For simplicity assume that $M$ is odd, so that there is a well-defined median voter. Let $m=\frac{M}{2}+\frac{1}{2}$. Thus a group of individuals has a majority if and only if it contains at least $m$ members.

In the initial situation, assume that individual $i$ gets benefits $\pi_{0}+d_{i}$, from shares in the firm. Here $\pi_{0}$ denotes the current value of the firm's profits and $d_{i}$ denotes the value of being able to purchase the good below the monopoly price. These benefits are experienced, whether or not the individual owns shares in the firm. ${ }^{7}$ We assume that the individuals are numbered so that $d_{1}<d_{2}<\ldots<d_{M}$. Apart from ruling out indifference, this is without loss of generality. Assume that decisions are made by majority rule, so a change will be introduced if at least half the members approve.

We consider the following model of a takeover attempt. First a raider decides whether or not to offer to purchase the shares from members at price $q$. Then the existing shareholders decide simultaneously and independently whether or not to accept. If the raider is successful, (s)he will increase profits to $\pi_{1}>\pi_{o}$ by raising price.

Suppose a raider offers to takeover the firm at a price of $q$ per share. Let $i$ denote a given member of the cooperative. Initially (s)he receives benefit $\pi_{0}+d_{i}$. Assume (s)he accepts the offer and the takeover fails, then (s)he can continue to receive the benefit $d_{i}$, hence his/her payoff is $q+d_{i}$. On the other hand if the takeover succeeds, the raider will adopt profit-maximizing policies and eliminate the benefit $d_{i}$, thus $i$ 's

\footnotetext{
${ }^{7}$ In these circumstances it may be profitable for the firm to practice price discrimination and sell at different prices to shareholders and non-shareholders. In an earlier paper, Kelsey and Milne (2006), we have investigated the implications of price discrimination in a related model. Here we simply assume that price discrimination is impossible either due to legislation or because consumers can resell.
} 
payoff will be $q$. If $i$ rejects the offer and the takeover fails his/her payoff will be unchanged at $\pi_{0}+d_{i}$. When the takeover succeeds the private benefit is eliminated, however the value of the shares will increase, thus $i$ 's payoff is $\pi_{1}$. The following table summarizes the pay-off of individual $i$ in the various possible outcomes. ${ }^{8}$

\begin{tabular}{|c|c|c|}
\hline & takeover succeeds & takeover fails \\
\hline$i$ accepts & $q$ & $q+d_{i}$ \\
\hline$i$ rejects & $\pi_{1}$ & $\pi_{0}+d_{i}$ \\
\hline
\end{tabular}

The following result says that a successful takeover is possible if and only if the amount by which the raider can increase the value of the firm is greater than the benefit which the median shareholder gets from the controlling the monopoly distortion.

Proposition 2.1 A necessary and sufficient condition for the existence of a subgame perfect equilibrium in pure strategies, in which the raider succeeds in taking over the firm is: $\pi_{1}-\pi_{o} \geqslant d_{m}$.

The following result characterizes the efficiency properties of the equilibrium. Let $\bar{d}=\frac{1}{M} \sum_{i=1}^{M} d_{i}$ denote the average (i.e. mean) benefit to a cooperative member.

Proposition 2.2 If $\bar{d}>d_{m}$ (resp. $\bar{d}<d_{m}$ ) then too many (resp., too few) takeovers occur in equilibrium. If $\bar{d}=d_{m}$, then the equilibrium is efficient, in the sense that takeovers occur if and only if they increase total surplus.

Proof. Takeovers are efficient if $n\left(\pi_{1}-\pi_{o}\right) \geqslant \sum_{i=1}^{M} d_{i}$ or $\pi_{1}-\pi_{o} \geqslant \bar{d}$. Thus only if $\bar{d}=d_{m}$ is the equilibrium efficient.

If $\bar{d}=d_{m}$, takeovers will occur if and only if they increase total surplus. Say that a cooperative is internally efficient if the level of externalities (direct or pecuniary) it

\footnotetext{
${ }^{8}$ Note that whether or not the takeover succeeds may depend upon individual $i$ 's decision. Thus 'takeover succeeds' and 'takeover fails' are not states in the sense of Savage (1954).
} 
provides for its members satisfies the Samuleson condition for public goods. There is a related result by Bowen (1943) who shows that if the median voter and the mean voter have the same preferences then majority voting will result in efficient provision of public goods. Together the two results imply that a cooperative which is internally efficient, can only be taken over when it is socially desirable in the sense that the raider increases the total surplus.

So far we have assumed that the $d_{i}$ are exogenous. However in practice these parameters can often be influenced by the design of the constitution of the cooperative and selection of members. Hansmann (1996) argues that cooperatives are careful to ensure that the preferences of their members are relatively similar. For instance in agricultural cooperatives members are given voting rights in proportion to their trade with the cooperative. As far as possible the firm should use its influence to ensure the preferences of the mean and median voter are similar. If the firm can ensure that $\bar{d}=d_{m}$ then takeovers occur if and only if they are efficient.

There is a potential distortion within cooperatives. If decisions are made by a majority vote, the outcome will coincide with the preference of the median voter. However the cost will be born by the mean voter. If the median and mean voter have very different preferences then it is possible that the median voter will use the cooperative to make implicit transfers from the mean voter to himself/herself. If such distortions occur, the cooperative is unlikely to be efficient.

\subsection{Sequential Offers}

We believe that our argument is reasonably robust and does not depend crucially on the details of the interaction between the raider and the cooperative. As an alternative consider the possibility that the raider approached the members sequentially rather 
than simultaneously. This situation could be modelled as an $n+1$ stage game. First the raider quotes a price $q$ at which (s)he is prepared to buy shares. Then each shareholder in turn decides whether or not to accept the offer, i.e. first individual 1 decides then individual 2 decides,..., finally individual $M$ decides. There is complete and perfect information.

The next result studies the equilibrium of the sequential model. We find that the necessary and sufficient condition for the takeover to succeed is the same as in the simultaneous model.

Proposition 2.3 In the sequential model of takeovers, a necessary and sufficient condition for the existence of a subgame perfect equilibrium in pure strategies, in which the raider succeeds in taking over the firm is: $\pi_{1}-\pi_{o} \geqslant d_{m}$.

The efficiency properties of the sequential takeover model are similar to those of the simultaneous move model. This follows since the necessary and sufficient condition for a successful takeover is the same in both cases.

\subsection{Constitutions for Cooperatives}

In those cases where the takeover fails, the raider does not succeed for the reasons identified in Grossman and Hart (1980). The existing shareholders free-ride on the price of shares. By not accepting the offer, shareholders benefit from the increase in price without contributing to the costs of the takeover. Grossman and Hart argue that firms have incentives to overcome the free-rider problem by adopting constitutions, which allow raiders to either compulsorily purchase minority shares or dilute the rights of minority shareholders. Alternatively it may be desirable for government to introduce legislation allowing compulsory purchase of minority shares (as in the UK). 
In the present context, the raider's behaviour is undesirable to existing cooperative members and probably society in general. It is in the interest of the cooperative to introduce a constitution, which gives strong protection to minority rights. This will make free-riding easier and consequently reduce the chances of a hostile takeover. Hansmann (1996) shows that most consumer cooperatives allocate voting rights in proportion to the fraction of the output purchased. This would be one way to protect against takeovers. It is worth noting that most governments offer separate laws dealing with cooperatives and business firms. Protection against takeover may be more desirable for cooperatives.

In practice, cooperatives do not act naively when faced with strategic players. Refsell (1914) documents how cooperative grain elevators were established in the mid-west despite a number of attempts by a cartel of grain dealers to prevent them. Both sides were clearly acting strategically. For instance, the for profit firms tried to organize boycotts to prevent the wholesalers in Chicago from dealing with cooperatives. In practice, shares in cooperatives are not freely traded. Members are often required to sell their shares back to the cooperative if they wish to leave. Decisions are made on the basis of 'one member one vote' not one 'share one vote'. Hence a potential raider would have to convince a majority of members not the holders of a majority of shares that (s)he was offering a good deal. These various legal restrictions make it harder to takeover a cooperative than is implied by our assumptions. Thus our model is, if anything, more favourable to the raider than institutions are in practice. 


\subsection{Alternative Assumptions}

This section considers some alternative assumptions and discusses how they would affect our conclusions. In particular we consider asymmetric information, the possibility that it takes more than a simple majority to turn the cooperative into a for-profit firm or that non-members benefit from externalities created by the cooperative.

Firstly we have used a model with symmetric information. It is difficult to give precise predictions about the effects of asymmetric information since there are many possible kinds of informational asymmetries. Generally the literature on information economics, shows that an agent with an informational disadvantage will ceteris paribus make lower profit. It seems most likely that the raider will have an informational disadvantage, in which case takeovers will be more difficult than in the symmetric information model.

Another implication of the absence of informational asymmetries is that members of the cooperative know whether or not their votes are pivotal. As a result pivotal voters reject the take-over, while non pivotal voters vote in favour. The effects of incomplete information are ambiguous. It is possible that some pivotal voters might not realise that they are pivotal and hence vote for the takeover when this is not actually in their interests. However it is equally possible that non-pivotal voters might vote against the takeover because of the possibility that they might be pivotal.

In practice, cooperatives may need a super-majority vote to sell the firm to an outsider, (i.e. it might require a two thirds or $75 \%$ majority to approve the sale). We believe that the issues raised in this paper are one of the main reasons that such rules are used. Often shares in cooperatives are not openly traded. Both possibilities tend to make takeovers even more difficult. This would tend to strengthen our conclusion that inefficient takeovers are unlikely to occur in equilibrium. However super-majority 
rules would have the effect of preventing some takeovers which increase social surplus.

It is possible that the cooperative generates externalities (either direct or pecuniary) for some nonmembers. For small group externalities, e.g. a group of farmers running a cooperative grain elevator or a professional partnership using a common client list, it is practical to include all or nearly all beneficiaries. For a firm which produced more widespread externalities (e.g. a firm such as Microsoft with global market power) it is almost inevitable that many nonmembers will also benefit. This would result in the firm producing a positive externality. For the usual reasons this externality would be under-produced in equilibrium. In particular too many takeovers would succeed in equilibrium. (Assuming the social objective is maximizing total surplus.) This problem would not arise if the cooperative either refuses to trade with nonmembers or charges non-members commercial prices. Both practices are not uncommon. (Even some for-profit companies practice price discrimination between shareholders and others.)

Our results would need to be modified if the raider received private benefits of control from a successful takeover. In this case (s)he can afford to pay more than the maximised profit per share, which will increase his/her chances of success. However note that the private benefit makes the reduction in total surplus from a takeover smaller than it would be otherwise. Indeed if the private benefit is greater than the total surplus in the initial situation then such a takeover would be efficient. On the other hand if the current cooperative members receive non-monetary benefits from the status quo this will mean the raider has to make a higher offer for the takeover to succeed. Hence takeovers will be less likely. Similarly if the firm were in a line of business in which for-profit firms were intrinsically more efficient then takeovers would be more likely than our analysis suggests. However as Hansmann (1996) argues 
there are many circumstances in which a cooperative form is more efficient, which would tend to reduce the raider's chances of success.

Although our model is somewhat stylized we believe that it is not highly unrealistic. One way a cooperative may be taken over by a for-profit firm is a two stage process. In the first the cooperative is converted into a limited liability company by giving the members equal (or pro rata) amounts of equity in the new company. In the second stage, an outsider makes a tender offer for the shares of the former cooperative. Our analysis would apply to the second stage of such a process.

\section{CONCLUSION}

We have shown that, under some assumptions, cooperatives are not vulnerable to takeover by a raider who wishes to turn them into a profit-maximizing firm, except in circumstances where the cooperative form is unlikely to be efficient. In this conclusion we argue that this analysis is more widely applicable since other market distortions can be analysed in a similar way. We consider oligopolistic industries, distortions in input markets and industries with externalities. Moreover the theory applies to a wider range of firms than cooperatives such as partnerships or for-profit firms where the shares are wholly or partly-owned by consumers or other trading partners.

\subsection{Oligopolistic Markets}

The analysis so far has considered a cooperative, which is the only producer in its industry. If instead the industry is oligopolistic, there is a second effect which also acts to make takeovers difficult. Reorganizing a cooperative as a for-profit firm will change the objective function of the firm and this will in turn change the product 
market equilibrium. If firms compete Cournot-style, the changes are likely to be unfavourable to the raider. Replacing a cooperative by a for-profit firm will cause that firm to charge a higher price and produce a lower quantity for any given market conditions. Rivals will respond by producing more output which will reduce the profits of the firm. (Provided reaction curves are downward sloping, as is usual under Cournot competition.) It is possible that this effect is sufficiently strong for the ex-post profit to be lower. For a more detailed discussion of the relation between corporate governance and product market equilibrium see Kelsey and Milne (2008). ${ }^{9}$

\subsection{Other Market Distortions}

So far we have focused on imperfect competition in output markets. However the analysis would also apply to some other market distortions. Similar arguments have been advanced to show that industrial democracy can reduce the impact of asymmetric information (Hansmann (1996)) and externalities (Kelsey and Milne (2006) and Roemer (1993)). Consider a firm which produces an externality. Then starting at the profit maximizing level, shareholders have an interest to reduce/increase a negative/positive externality since a change will have a second order effect on profits but the direct affect on utility will be first order.

Our theory can be modified to study a firm which provides an externality for its owners. The variable $d_{i}$ can be reinterpreted as as the net benefit individual $i$ gets from a positive externality produced by the firm or the value to individual $i$ of controlling a negative externality. In our model the benefits are received whether or not the individual owns shares in the firm. This assumption is clearly valid for physical externalities such as pollution. It is likely to hold for most pecuniary externalities

\footnotetext{
${ }^{9}$ Related results on strategic delegation in oligopolistic industries can be found in Fershtman and Judd (1987) and Vickers (1985).
} 
between firms. It may or may not hold for other externalities.

\subsection{Local Public Companies}

In this section we argue that local public companies have many features in common with cooperatives and review the empirical evidence. In both cases the organizational form enables owner-shareholders to economize on monitoring costs, and/or other market distortions.

Franks, Mayer, and Rossi (2009) (henceforth FMR) examine detailed data on the evolution of ownership patterns of 60 U.K. firms over the twentieth century. In the first half of the century, legal investor protection was weak, yet the regional stockmarkets thrived. These markets traded local firms and their shares were held largely by local shareholders. According to FMR informal mechanisms of trust were used to influence boards of local directors. They observe that even though there was dispersion of ownership over time, local concentration of ownership continued to be dominant. FMR argue that the evidence on takeovers shows that the same price was offered to all shareholders even in the absence of investor regulatory protection.

Later in the century, this local dominance declined as regional stock-markets were replaced by the London market and institutional shareholders representing geographically dispersed shareholders became more important. Trust and local informal mechanisms were replaced by more formal legal mechanisms.

In the study by FMR, it would be instructive to see from U.K. data, if local public companies attracted shareholders who faced pecuniary externalities that arose from the actions of the firm, either as consumers of their output or suppliers of inputs. These overlapping interests may have been formalized by mergers and takeovers so that potential conflicts could have been resolved. Over the twentieth century, as 
geographic dispersion of the firms' activities grew by acquisitions and shareholders became more geographically dispersed, this pecuniary effect may have diminished. During this time, due to a number of factors, mutual or cooperative firms became less common. This could be explained by the same process of erosion in local trust mechanisms for monitoring. An increase in regulatory protection reduced the need for less formal systems of monitoring. Local pecuniary effects were eroded by increased competition and direct externalities were reduced due to dispersion and mobility of firms and investors.

Another possible application would be to a conventional company created and owned by a small number of businesses that are interested in purchasing its product. This is similar to a local public company, since any externalities are confined to a relatively small group of economic agents. If this similarity in product and input market imperfections for cooperatives and corporations is important for governance structures, then our argument for the stability of ownership, and internalization of externalities, would operate for both cooperatives, locally owned public companies and public companies with customer-supplier relationships.

\section{A APPENDIX}

This appendix contains the proofs of our main results.

\section{A.1 Simultaneous Move Takeover Model}

If $q \geqslant \pi_{1}$, the raider can never make a positive profit, hence we may assume $\pi_{1}>q>$ $\pi_{0}$. Let $L=\left\{i ; \pi_{0}+d_{i} \leqslant q\right\}$ be the set of individuals whose total benefit from the cooperative is less than the raider's offer and let $\ell$ denote the number of individuals 
in this set. Of course $L$ depends on the price $q$ at which the raider offers to buy the shares. Let $G=\{1, \ldots, M\} \backslash L$ denote the remaining individuals. Loosely speaking $G$ are the gainers and $L$ are the losers from having production organized in a cooperative.

Lemma A.1 If $m>\ell$, then in any pure strategy Nash equilibrium of the subgame following the raider's offer, precisely $m-1$ individuals accept. In particular all members of $L$ accept the offer.

Proof. First we shall check that such a profile is indeed an equilibrium. A member who accepts the offer will get pay-off $q+d_{i}$. This would fall to $\pi_{0}+d_{i}$ if (s)he rejected it. Now consider an individual, $j$, say who rejects the offer in this profile. By construction $j$ is not in $L$ and hence $\pi_{0}+d_{j}>q$. Moreover such an individual is pivotal. By rejecting the offer $j$ gets pay-off $\pi_{0}+d_{j}$. If instead $j$ accepted the offer his/her pay-off would fall to $q$. This confirms that rejection is a best response. It follows that this profile of strategies is indeed an equilibrium.

Now to demonstrate that there are no other pure strategy Nash equilibria. We shall consider all other possible profiles in turn and show that in each case at least one individual has a profitable deviation. First consider profiles in which there are $r>m$ acceptances. In this case the raider will take control of the firm and raise the share value to $\pi_{1}$. Consider an individual who accepts the raider's offer. Currently (s)he receives pay-off $q$. If instead (s)he rejected the raider's offer, the bid would still succeed. Hence his/her payoff would be $\pi_{1}>q .{ }^{10}$

Secondly consider the case where there are $r=m$ acceptances. Since $m>\ell$, there exists an individual $\tilde{\imath} \notin L$ who accepts the raider's offer. Such an individual must be pivotal. If instead (s)he rejected the raider's offer, as before, his/her pay-off would be $\pi_{0}+d_{i}$, which is greater than his/her current pay-off, $q$.

\footnotetext{
${ }^{10}$ Note such individuals are essentially using the free-riding strategy identified in Grossman and Hart (1980).
} 
Thirdly consider a profile, in which there are $r=m-1$ acceptances and there exists $\hat{\imath} \in L$, who does not accept the offer. Then $\hat{\imath}$ 's current payoff is $\pi_{0}+d_{\hat{\imath}}$. This would increase to $q$ if instead $\hat{\imath}$ accepted the offer.

Finally consider a profile, in which there are $r<m-1$ acceptances. Consider an individual, $k$, who currently is rejecting the raider's offer. If (s)he deviated and accepted (s)he would receive $q+d_{k}>\pi_{0}+d_{k}$, which is his/her current pay-off.

Lemma A.2 If $\ell \geqslant m$, then in any pure strategy Nash equilibrium of the subgame following the raider's offer precisely $m$ individuals accept. In particular all those who accept are members of $L$.

Proof. First we shall check that a profile of this form is indeed an equilibrium. In these profiles the raider succeeds in taking over the firm and hence no private benefits will be received ex post. Thus an individual who rejects the offer will get pay-off $\pi_{1}$. If instead (s)he accepted the offer his/her pay-off would fall to $q$. All individuals who accept the offer are pivotal and receive pay-off $q$. If one of them deviated and rejected the offer (s)he would receive $\pi_{0}+d_{i}<q$, since all individuals who accept the offer are in $L$.

Now to demonstrate that there are no other pure strategy Nash equilibria. We shall consider all other possible profiles in turn and show that in each case at least one individual has a profitable deviation.

First consider profiles in which there are $r \geqslant m+1$ acceptances. In this case the raider will take control of the firm, raise the share value to $\pi_{1}$ and eliminate the private benefits. Consider an individual who accepts the raider's offer. Currently (s)he receives pay-off $q$. If instead (s)he rejected the raider's offer, the bid would still succeed. Hence his/her payoff would be $\pi_{1}>q$. 
Secondly consider the case where there are $r=m$ acceptances and there exists an individual $\tilde{\imath} \notin L$ who accepts the raider's offer. Note that such an individual is pivotal. If instead (s)he rejected the raider's offer as before his/her pay-off would be $\pi_{0}+d_{i}$, which is greater than his/her current pay-off, $q$.

Thirdly consider a profile, in which there are $r=m-1$ acceptances. Since $\ell>m$ there must exist an individual $j \in L$ who rejects the offer. If instead (s)he accepted as before his/her pay-off would be $q$, which is greater than his/her current pay-off, $\pi_{0}+d_{j}$. Note that $j$ must be pivotal.

Finally consider a profile in which there are $r<m-1$ acceptances. Let $k$ be an individual who rejects the raider's offer. He/she is not pivotal, so if instead (s)he accepted the raider's offer, his/her pay-off would increase from $\pi_{0}+d_{k}$ to $q+d_{k}$. This completes the proof.

Proof of Proposition 2.1 Since individuals will not accept the offer unless it is in their interest to do so, for the offer to succeed it is necessary that $q$ be sufficiently high that $\{1, \ldots, m\} \subseteq L .\left(\right.$ Recall $\left.L=\left\{i: d_{i} \leqslant q-\pi_{o}\right\}.\right)$

Suppose that $\pi_{1}-\pi_{o}<d_{m}$. To make a profit it is necessary that $\pi_{1} \geqslant q$. By Lemma A.1, if the raider made an offer $q$ such that $q-\pi_{o}<d_{m}$ she would not get enough acceptances to gain control of the firm. Hence the raider would make a loss of $(m-1)\left(\pi_{0}-q\right)$. It follows that making such an offer is not part of any subgame perfect equilibrium.

Now suppose that $\pi_{1}-\pi_{o} \geqslant d_{m}$. If the raider offers to buy the shares at price $q=\pi_{o}+d_{m}$ then $L=\{1, \ldots, m\}$. (We assume that indifference is resolved in favour of the raider.) By Lemma A.2 precisely $m$ individuals will accept the offer hence the raider will gain control of the firm and make a profit of $m\left(\pi_{1}-q\right)$. 
In the subgames described in Lemmas A.1 and A.2, there are multiple Nash equilibria. As in other situations where equilibrium is not unique, this creates a potential coordination problem, i.e. how do players know which of the possibly many equilibrium strategies they should play? We believe the coordination problem here is not as severe as it is in some other games because this game is not symmetric. Hence there are many coordination devices which could be used to select a particular Nash equilibrium. Consider, for instance, the case in Lemma A.2 where the takeover succeeds. Then some but not all of the group of individuals who get low benefit from the cooperative vote for the takeover. Let $L^{+}\left(\right.$resp. $\left.L^{-}\right)$denote those members of $L$ who vote for (resp. against) the takeover. The above proof shows that any situation where $m$ individuals are in $L^{-}$is a Nash equilibrium. One of these in particular is focal, where the $m$ individuals with the lowest benefits from the cooperative vote for the takeover. (Recall this is a game of complete and perfect information so all players know the pay-offs of the others.)

\section{A.2 Sequential Takeover Model}

This section of the appendix contains proofs of our claims about the sequential move takeover model. For this section we do not make the assumption that $d_{1}<d_{2}<$ $\ldots<d_{M}$, since it is not without loss of generality in the sequential move game. Recall we have defined $L=\left\{i ; \pi_{0}+d_{i} \leqslant q\right\}$ to be the set of individuals whose total benefit from the cooperative is less than the raider's offer and $\ell$ to denote the number of individuals in this set. Let $G=\{1, \ldots, M\} \backslash L$ denote the remaining individuals. Loosely speaking $G$ are the gainers and $L$ are the losers from having production organized in a cooperative. First we shall analyse the subgame following the raider's offer. 
Lemma A.3 If $m>\ell$ then in the sub-game following the raider's offer a takeover will not succeed. In particular all members of $L$ will accept the offer and the first $m-1-\ell$ members of $G$ will accept. The remaining members of $G$ will reject the offer.

Proof. We claim that the following set of strategies are a subgame perfect equilibrium of the sub-game following the raider's offer.

- Members of $L$ accept the raider's offer unless at least $m+1-\ell$ members of $G$ have already accepted.

- Members of $G$ will accept the takeover bid if less than $m-1-\ell$ members of $G$ have accepted previously and will reject otherwise.

To check this constitutes a sub-game perfect equilibrium. First note that it is clear no member of $L$ will reject the offer on the equilibrium path. (Rejecting would reduce the member's own pay-off and make the take-over less likely to happen.) Therefore we shall not consider any history in which members of $L$ reject the takeover. ${ }^{11}$

- To check members of $L$ are playing best responses, consider a given individual, $\lambda \in L$. There are three sub-cases to consider depending on the history.

- At most $m-1-\ell$ members of $G$ have already accepted the raider's offer. In this case, the offer will be rejected regardless of what $\lambda$ decides. Accepting is a best response for $\lambda$ since it yields $q+d_{\lambda}>\pi_{o}+d_{\lambda}$, which is his/her pay-off if (s)he rejects.

\footnotetext{
${ }^{11}$ It might be in the interest of a member of $L$ to reject the offer if sufficiently many members of $G$ had accepted to make the success of the takeover a certainty. However such a history can only arise if there are multiple deviations from the equilibrium path. One can easily check that the proposed subgame perfect equilibrium is robust to such deviations.
} 
- Precisely $m-\ell$ members of $G$ have already accepted the offer. In this case $\lambda$ is pivotal, by accepting (s)he will obtain $q>\pi_{o}+d_{\lambda}$.

- At least $m+1-\ell$ members of $G$ have already accepted. In this case the offer will succeed regardless of what $\lambda$ decides. Rejecting is a best response for $\lambda$ in this case since it yields $\pi_{1}+d_{\lambda}>q+d_{\lambda}$, which is his/her pay-off if $(\mathrm{s})$ he accepts.

- To see that members of $G$ are playing best responses, consider a given individual, $g \in G$. There are three possible cases to consider:

- If if less than $m-1-\ell$ members of $G$ have accepted previously then the takeover will fail whatever $g$ decides. By accepting $g$ gets pay-off $q+d_{g}>\pi_{o}+d_{g}$, which is his/her pay-off if (s)he rejects.

- If precisely $m-1-\ell$ members of $G$ have accepted previously then $g$ is pivotal. In equilibrium $g$ will reject the offer after this history. This yields $g$ pay-off, $\pi_{o}+d_{g}>q$, which is his/her pay-off if (s)he accepts.

- If at least $m-\ell$ members of $G$ have accepted previously then the takeover will succeed regardless of what $g$ does. In this case $g$ by rejecting gets payoff $\pi_{1}>q$, which is what (s)he would have received if (s)he had accepted.

Lemma A.4 If $m \leqslant \ell$ then in a subgame perfect equilibrium of the sequential move game, all members of $G$ and the first $\ell-m$ members of $L$ will reject the offer and the remaining members of $L$ will accept.

Proof. We claim,the following set of strategies constitute a subgame perfect equilibrium: 
- Members of $L$ reject the raider's offer if less than $\ell-m$ members of $L$ have rejected previously and will accept otherwise.

- Members of $G$ will reject the raider's offer unless $\ell-m-1$ members of $L$ have rejected previously in which case they accept.

To check this constitutes a sub-game perfect equilibrium. We shall not consider histories where members of $G$ accept the raider's offer. It is easy to show that such individuals are not playing best responses.

- To check members of $L$ are playing best responses, consider a given individual, $\lambda \in L$. There are three sub-cases to consider depending on the history.

- At most $\ell-m-1$ members of $L$ have previously rejected the raider's offer. In this case if $\lambda$ rejects and all subsequent individuals follow the equilibrium strategy then the take-over will succeed. By rejecting $\lambda$ raises his/her pay-off from $q$ to $\pi_{1}$.

- Precisely $\ell-m$ members of $L$ have previously rejected the raider's offer. In this case individual $\lambda$ is pivotal. By accepting (s)he raises his/her pay-off from $\pi_{o}+d_{\lambda}$ to $q$.

- At least $\ell-m+1$ members of $L$ have previously rejected the raider's offer. In this case the take-over will fail regardless of what $\lambda$ does. By accepting $\lambda$ raises his/her pay-off from $\pi_{o}+d_{\lambda}$ to $q+d_{\lambda}$.

- To see that members of $G$ are playing best responses, consider a given individual, $g \in G$. There are three sub-cases to consider:

- The takeover will succeed regardless of what $g$ does. Rejecting the offer raises $g$ 's pay-off from $q$ to $\pi_{1}$. 
- Individual $g$ is pivotal. Rejecting the offer raises $g$ 's pay-off from $q$ to $\pi_{o}+d_{g}$

- The takeover will fail regardless of what $g$ does. Rejecting the offer will lower $g$ 's pay-off from $q+d_{g}$ to $\pi_{o}+d_{g}$.

Proof of Proposition 2.3 For the offer to succeed it is necessary that $q$ be sufficiently high that $|L| \geqslant m .{ }^{12}$ Recall $L=\left\{i ; \pi_{0}+d_{i} \leqslant q\right\}$ denotes the set of individuals whose total benefit from the cooperative is less than the raider's offer.

Suppose that $\pi_{1}-\pi_{o}<d_{m}$. To make a profit it is necessary that $\pi_{1} \geqslant q$. By Lemma A.3, if the raider made an offer $q$ such that $q-\pi_{o}<d_{m}$ (s)he would not get enough acceptances to gain control of the firm. Hence the raider would make a loss of $(m-1)\left(\pi_{0}-q\right)$. It follows that making such an offer is not part of any subgame perfect equilibrium.

Now suppose that $\pi_{1}-\pi_{o} \geqslant d_{m}$. If the raider offers to buy the shares at price $q=\pi_{o}+d_{m}$ then $|L|=m$. By Lemma A.4 precisely $m$ individuals will accept the offer hence the raider will gain control of the firm and make a profit of $m\left(\pi_{1}-q\right)$.

\section{References}

Bowen, H. R. (1943): "The Interpretation of Voting in the Allocation of Economic Resources," Quarterly Journal of Economics, 58, 27-48.

Corneo, G. (1997): "Taxpayer-Consumers and Public Pricing," Economics Letters, $57,235-240$.

\footnotetext{
${ }^{12}$ Here $|L|$ denotes the numbers of elements in the set $L$.
} 
Demichelis, S., and K. Ritzberger (2006): "Corporate Control and the Stock Market," working paper, Institute of Advanced Studies Vienna.

Dow, G. K., and G. Skillman (2007): "Collective Choice and Control Rights in Firms," Journal of Public Economic Theory, 9, 107-125.

FArrell, J. (1985): "Owner-Consumers and Efficiency," Economics Letters, 19, 303-306.

Fershtman, C., And K. L. Judd (1987): "Equilibrium Incentives in Oligopoly," American Economic Review, 77, 927-940.

Franks, J., C. Mayer, and S. Rossi (2009): "Ownership: Evolution and Regulation," Review of Financial Studies, forthcoming.

Gabszewicz, J. J., And J. P. Vial (1972): "Oligopoly a la Cournot in a General Equilibrium Analysis," Journal of Economic Theory, 4, 381-400.

Grossman, S., and O. Hart (1980): "Takeover Bids, the Free Rider Problem, and the Theory of the Corporation," Bell Journal of Economics, 11, 42-64.

Hansmann, H. (1996): The Ownership of Enterprise. Harvard University Press, Cambridge, Mass.

Hart, O., And J. Moore (1996): “The Governance of Exchanges: Members' Cooperatives versus Outside Ownership," Oxford Review of Economic Policy, 12, 53-69.

Kelsey, D., And F. Milne (2006): "Externalities, Monopoly and the Objective Function of the Firm," Economic Theory, 29, 143-151.

_ (2008): "Imperfect Competition and Corporate Governance," Journal of Public Economic Theory, 10, 1115-1141. 
Refsell, O. (1914): "The Farmers' Elevator Movement," Journal of Political Economy, 22, 872-895 and 969-991.

Renstrom, T., and E. Yalcin (2003): "Endogenous Firm Objectives," Journal of Public Economic Theory, 5, 67-94.

Roemer, J. E. (1993): "Would Economic Democracy Decrease the Amount of Public Bads?," Scandinavian Journal of Economics, 95, 227-238.

Savage, L. J. (1954): Foundations of Statistics. Wiley, New York.

Vickers, J. (1985): "Delegation and the Theory of the Firm," Economic Journal, 95 (conference supplement), 138-147. 